[0212-7199 (2008) 25: 6; pp 284-286] ANALES DE MEDICINA INTERNA Copyright (C) 2008 ARAN EDICIONES, S.L.

AN. MED. INTERNA (Madrid) Vol. 25, N. ${ }^{\circ} 6$, pp. 284-286, 2008

\title{
Tromboflebitis supurada laterocervical tras cateterización venosa central
}

\author{
A. RAMOS MARTÍNEZ, I. SÁNCHEZ ROMERO ${ }^{1}$, P. A. SAURA LORENTE ${ }^{2}$, \\ A. PARAJÓN DÍAZ
}

Servicio de Medicina Interna, ${ }^{1}$ Micorgiología, ${ }^{2}$ Radiología y ${ }^{3}$ Neurocirugía. Servicio de Medicina Interna III. Hospital Universitario Puerta de Hierro. Madrid

SUPPURATIVE THROMBOPHLEBITISIS CENTRAL VENOUS CATHETERIZATION

\begin{abstract}
RESUMEN
La tromboflebitis supurada es una complicación muy infrecuente de la cateterización venosa central. La mayoría de los casos están producidos por especies de estafilococos. Se presenta el caso de una mujer de 22 años natural de Colombia sin hábitos tóxicos que estaba ingresada tras haber sido intervenida de un astrocitoma temporal izquierdo de grado II. A los 9 días de la implantación de un catéter en la vena subclavia derecha presentó fiebre elevada, escalofríos y tiritona junto a tumefacción progresiva laterocervical derecha y odinofagia. Tenía leucocitosis de 26.300 células/ $\mu 1$ y líquido cefalorraquídeo normal. Tras retirar el catéter se aisló Staphylococcus aureus en la punta del catéter y en los cuatro frascos obtenidos en los hemocultivos. Una TAC de cabeza y de cuello con contraste evidenció distensión y ausencia de contraste en la vena yugular interna derecha. La paciente evolucionó satisfactoriamente con cloxacilina, gentamicina y heparina de bajo peso molecular.
\end{abstract}

PALABRAS CLAVE: Venas yugulares. Trombosis venosa. Bacteriemia. Staphylococcus aureus.

\begin{abstract}
Suppurative thrombophlebitisis a very infrequent complication of the central venous catheterization. The majority of the cases are produced by species of staphylococci. A 22-year-old colombian-woman, student, without toxic habits was admitted because of temporary left astrocytoma (grade II). Nine days after implementing a catheter in the right subclavian vein she presented high fever $\left(39.5^{\circ} \mathrm{C}\right)$, shivers, progressive right side neck swelling and odinofagia. She had leukocytosis $(26,300 \mathrm{cells} / \mathrm{\mu l})$ and normal cerebrospinal fluid. After withdrawing the catheter, Staphylococcus aureus was isolated in the tip of the catheter and in four bottles of blood cultures. A neck CT demonstrated expansion and absence of contrast in the right internal jugular vein. The patient evolved satisfactorily with cloxacillin, gentamycin and low molecular weight heparin.
\end{abstract}

KEY WORDS: Jugular veins. Venous trombosis. Bacteremia. Staphylococcus aureus.

Ramos Martínez A, Sánchez Romero I, Saura Lorente PA, Parajón Díaz A. Tromboflebitis supurada laterocervical tras cateterización venosa central. An Med Interna (Madrid) 2008; 25: 284-286.

\section{INTRODUCCIÓN}

La trombosis venosa es una complicación frecuente en pacientes sometidos a la colocación de catéteres centrales (CC) $(1,2)$. Sin embargo, la incidencia tromboflebitis supurada (TFS) en estos pacientes sólo del 0,14\%, siendo el Staphylococcus aureus el patógeno más frecuentemente implicado (3). La producción de determinaqdas enzimas como las coagulasas favorece su adherencia a la fibrina formada sobre estos dispositivos $(2,4)$.

\section{CASO APORTADO}

Mujer de 22 años natural de Colombia, estudiante, sin hábitos tóxicos que estaba tras haber sido intervenida de un astrocitoma tem- poral izquierdo de grado II. El estudio de coagulación preoperatorio fue normal. El día de la intervención se intentó sin éxito de canalizar la vena yugular interna derecha, posteriormente se implantó un catéter central (CC) en la vena subclavia ipsilateral. A los 9 días presentó fiebre elevada $\left(39,5^{\circ} \mathrm{C}\right)$, escalofríos y tiritona junto a tumefacción progresiva laterocervical derecha y odinofagia. En la exploración física se evidenció un buen estado general con 95/60 mm Hg de presión arterial, leve abombamiento de la parte derecha del velo del paladar y tumefacción muy dolorosa a la palpación de la región laterocervical derecha sin crepitación (Fig. 1). En el punto de entrada del $\mathrm{CC}$ no se evidenciaban signos inflamatorios. En la analítica presentaba leucocitosis de 26.300 células/ $\mu$ (95\% neutrófilos, sin desviación izquierda), líquido cefalorraquídeo normal con cultivo negativo. Se retiró el CC cultivando su punta y se extrajeron 2 hemocultivos. Se pautó vancomicina $1 \mathrm{~g} / 12 \mathrm{~h}$ por vía endovenosa. Una TAC de cabeza y de cuello con contraste evidenció la ausencia de contraste en las venas yugular interna (que se encontraba al distendida) y externa

Trabajo aceptado: 16 de enero de 2008

Correspondencia: Antonio Ramos Martínez. Servicio de Medicina Interna III. Hospital Universitario Puerta de Hierro. C/ San Martín de Porres, 4. 28050 Madrid.e-mail: antrammar@yahoo.es 


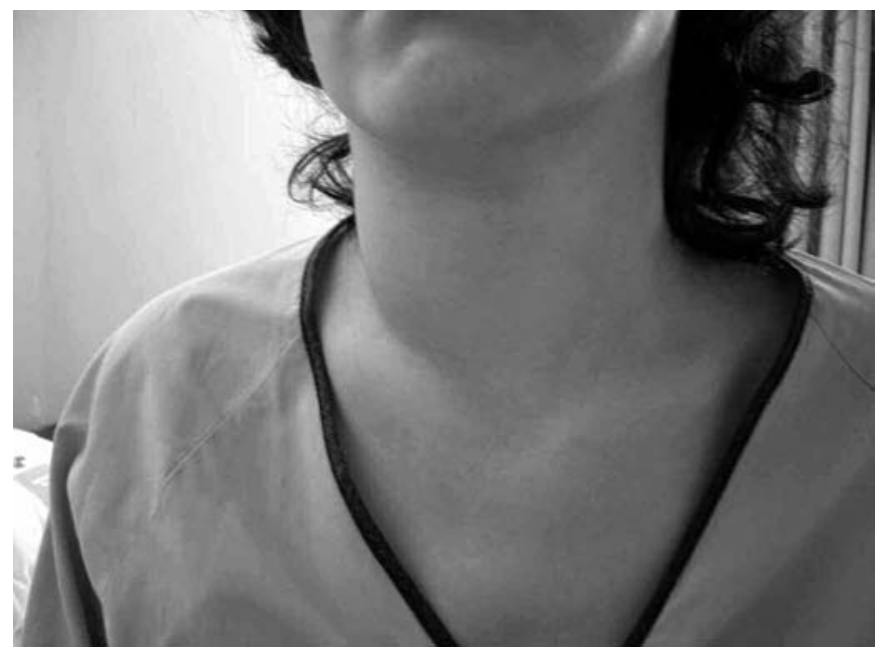

Fig. 1. Tumefacción en región laterocervical derecha.

derechas con desdibujamiento de la grasa perivascular, engrosamiento de la fascia cervical superficial y edema en el músculo esternocleidomastoideo (Fig. 2). No se visualizaron colecciones purulentas ni gas. Se añadió enoxaparina $60 \mathrm{mg} / 12 \mathrm{~h}$ por vía subcutánea.

A las 48 horas se aisló Staphylococcus aureus sensible a los antibióticos testados excepto penicilina y ampicilina. en los hemocultivos (4 de 4 frascos) y en la punta del catéter (cultivo semicuantitativo con más de 15 colonias/placa). Se cambió el tratamiento a cloxacilina $2 \mathrm{~g} / 4 \mathrm{~h}$ y gentamicina $60 \mathrm{mg} / 8$ horas por vía intravenosa. La gentamicina se retiró el cuarto día y la cloxacilina se mantuvo hasta cumplir 4 semanas. Una radiografía de tórax y un ecocardiograma transtorácico no mostraron alteraciones significativas. Los hemocultivos obtenidos el sexto día de tratamiento fueron negativos. La paciente presentó de picos febriles (hasta $38,2^{\circ} \mathrm{C}$ ) durante la primera semana tras la retirada del CC. La tumefacción del cuello fue disminuyendo lentamente durante 3 semanas con desaparición del dolor. A partir de la tercera semana se sustituyó la heparina por acenocumarol que se mantuvo 3 meses.

\section{DISCUSIÓN}

La tromboflebitis supurada es una complicación muy infrecuente de la cateterización venosa central (1). La mayoría de los casos están producidos por especies de estafilococos $(2,4)$. En ocasiones los casos de TFS yugular se originan por extensión de focos sépticos próximos como ocurre en el síndrome de Lemierre o en adictos tras la autoadministración de sustancias tóxicas por vía endovenosa $(5,6)$. Aunque los pacientes con neoplasias que padecen bacteriemia asociada a catéter por $S$. aureus presentan un mayor riesgo de TFS, la escasa agresividad histológica y limitada extensión del tumor que padecía la paciente sugieren que su enfermedad cerebral no tuvo una influencia relevante en la aparición de la TFS (2).

Como en ocurrió en el caso presentado, los pacientes con TFS yugular pueden presentar tumefacción dolorosa del cue-

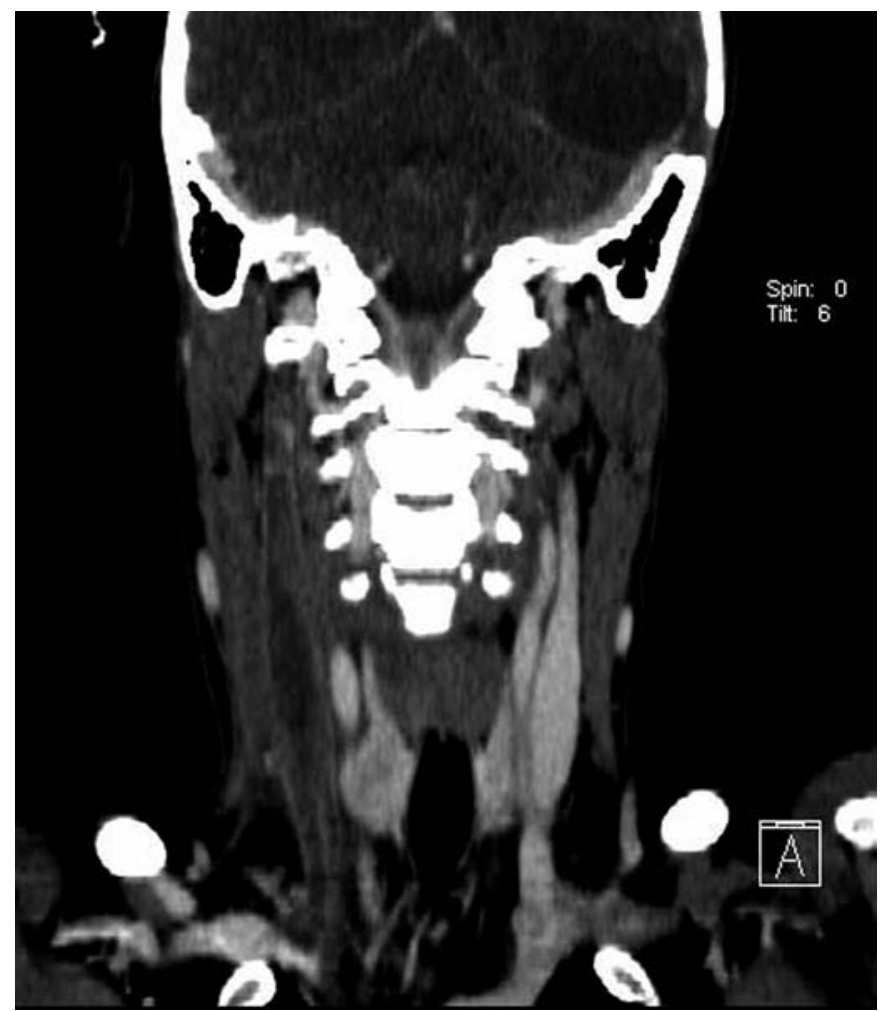

Fig. 2. TAC cervical (reconstrucción en un plano coronal) donde se objetiva ausencia de contraste en el interior de la vena yugular interna derecha (flechas).

llo, aunque en ocasiones no experimentan ningún síntoma (7). No es excepcional el desarrollo de focos sépticos secundarios o la propagación intracraneal de la trombosis como está descrito en casos precedentes (7).

Mediante la ecografía doppler se puede realizar el diagnóstico en muchas ocasiones pero tiene dificultades para detectar trombosis de pequeña longitud o cercanas al hueco supraclavicular. La TAC con contraste y la resonancia magnética presentan una mejor sensibilidad y permite además la detección de abscesos o celulitis perivasculares (4).

Como en otras infecciones intravasculares, se recomienda mantener el tratamiento antibiótico al menos 4 semanas (6). Es obligado retirar el CC, inclusos en los casos pacientes portadores de CC de larga duración (8). El tratamiento anticoagulante con heparina se emplea para reducir el riesgo de embolismo séptico (9). Afortunadamente la mayoría de los casos de TFS evolucionan bien con el tratamiento mencionado, aunque en ocasiones es necesario emplear tratamiento trombolítico para movilizar los restos de trombo que permanecían adheridos a la pared de la vena si el foco séptico persiste $(8,10)$. La trombectomía y la resección parcial de la vena yugular interna son procedimientos empleados muy infrecuentemente que pueden utilizarse si hay una progresión del infección $(9,10)$. 


\section{Bibliografía}

1. Raad I, Luna M, Khalil S, Costerton J, Lam C, Bodey G. The relationship between the thrombotic and infectious complications of central venous catheters. JAMA 1994; 271: 1014-6.

2. Ghanem GA, Boktour M, Warneke C, Pham-Williams T, Kassis C, Bahna P, et al. Catheter-related Staphylococcus aurues bacteremia in cancer patients: high rate of complications with therapeutic implications. Medicine (Baltimore) 2007; 86: 54-60.

3. Rello J, Jubert P, Esandi ME, Valles J. Specific problems of arterial, Swan-Ganz, and hemodialysis catheters. Nutrition 1997; 13 (Supl.): 36S-41S.

4. Van Rooden CJ, Schippers EF, Barge RM, Rosendaal FR, Guiot HF, van der Meer FJ, et al. Infectious complications of central venous catheters increase the risk of catheter related thrombosis in hematology patients: a prospective study. J Clin Oncol 2005; 23: 2655-60.

5. Lemierre A. On certain septicemias due to anaerobic organisms. Lancet
1936; 1: 701-3.

6. Fäh F, Zimmerli W, Jordi M, Schoenenberger RA. Septic deep venous thrombosis in intravenous drug users. Swiss Med Wkly 2002; 132: 38692.

7. Walsh DC, Kakkar AK. Thromboembolism in brain tumors. Curr Opin Pulm Med 2001; 7: 326-31.

8. Reper P, Van Der Rest P, Creemers A, Vandenen D, Vanderkelen A. Medical treatment of a central vein suppurative thrombosis with cerebral metastatic abcesses in a burned child Burns 2001; 27: 662-3

9. Gidley PW, Ghorayeb BY, Stiernberg CM. Contemporary management of deep neck space infections. Otol Head Neck Surg 1997; 116: 16-22.

10. Volkow P, Cornejo-Juárez P, Arizpe-Bravo AB, García-Méndez J, Baltazares-Lipp E, Pérez-Padilla R. Catheter-related septic thrombophlebitis of the great central veins successfully treated with low-dose streptokinase thrombolysis and antimicrobials. Thromb J 2005; 3: 11-4 